\title{
Eliminación de Grasas del Suero de Queso para Obtener Proteínas y Lactosa
}

Rosane R. Souza, Marcelino L. Gimenes, Sílvio C. Costa y Carmen M.O. Müller Universidad Estadual de Maringá, Departamento de Engenharia Química, Bloco D-90, Avenida Colombo № 5790, 87020-900 Maringá, PR-Brasil (e-mail: rosaners@gmail.com)

\section{Resumen}

Se estudiaron procesos de pre-tratamiento para la eliminación de grasas y sales minerales del suero de queso tipo ácido, para el aprovechamiento del contenido de proteínas y lactosa. Se analizaron procesos de separación tales como centrifugación y precipitación termo-cálcica seguidos de una etapa de micro-filtración. El proceso de centrifugación combinado con micro-filtración se mostró más eficiente en lo que se refiere a la eliminación de grasa, obteniéndose un promedio de $90 \%$ de recuperación de proteínas y de lactosa.

Palabras claves: suero de queso, micro-filtración, proteínas, lactosa

\section{Fat Removal from Whey to Obtain Proteins and Lactose}

\begin{abstract}
Pre-treatment processes to remove fat and mineral salts from acid whey in order to recover its proteins and lactose contents were studied. Separation processes such as centrifugation and thermocalcic precipitation followed by microfiltration were analyzed. The centrifugation process combined with microfiltration process was more efficient for removing fat, resulting in an average lactose and protein recovery of $90 \%$.
\end{abstract}

Keywords: whey, microfiltration, proteins, lactose 


\section{INTRODUCCIÓN}

La creciente preocupación en mejorar el aprovechamiento de recursos naturales evitando, de esta forma, perjuicios al medio ambiente, hace que exista una búsqueda permanente de nuevos productos y tecnologías que optimicen los procesos, disminuyendo costos de producción y dando valor agregado a residuos con potencial comercial. La utilización de proteínas como ingredientes funcionales, es un ejemplo de estas nuevas tecnologías que torna posible el desarrollo de productos con características especiales, mejorando la calidad de los productos tradicionales, además de agregar valor a subproductos, que con frecuencia representan un problema para industrias, como es el caso del suero de queso (Atra et al., 2005; Richards, 2002).

En Brasil, por ejemplo, el suero resultante de la industria quesera es, en la mayoría de los casos, simplemente descartado en alcantarillas o manantiales o utilizado, esporádicamente, como ración animal. Además, de representar un problema ambiental, se deja de emplear un producto noble, en aplicaciones que le darían un mayor valor comercial (Antunes, 2003).

Varias tecnologías pueden ser utilizadas para el aprovechamiento del suero de queso, entre ellas, el proceso de separación con membranas. La industria láctea es una de las mayores defensoras de los sistemas con membranas, utilizando esta tecnología desde su inicio para concentrar y fraccionar el suero de queso, así como para tratar el agua residual (Muñi et al., 2005; Brião, 2007).

Todo proceso que incluye el fraccionamiento y la concentración de las proteínas del suero debe considerar también la recuperación de la lactosa, que es el componente que se encuentra en mayor cantidad y la principal responsable por la elevada carga orgánica del suero. Por otra parte, la lactosa por ser una fuente de material energético puede ser utilizada en diversos procesos biotecnológicos, y es un componente muy usado en las industrias alimenticias y farmacéuticas. Así el fraccionamiento del suero en lactosa y proteínas representa una posibilidad que permite la utilización de los constituyentes de mayor importancia comercial presentes en los suero de queso (Chollangi y Hossain, 2007; Bund y Pandit, 2007).

Para la obtención de concentrados proteicos y lactosa de excelente calidad y alto valor agregado, es importante la eliminación de grasas del suero de queso. Esta eliminación es considerada esencial porque las grasas constituyen uno de los agentes de saturación que pueden contribuir, por ejemplo, para la disminución del flujo en el proceso con membranas, lo que puede ocasionar la obtención de productos con sabores alterados durante el almacenamiento (Nakay y Modler, 2000).

Por lo tanto, existen varios procesos que pueden ser utilizados para la eliminación de grasas del suero lácteo con la finalidad de promover mejorías en el proceso de concentración proteica, a saber: centrifugación, filtración, micro-filtración, etc. La centrifugación es el proceso convencionalmente utilizado para la eliminación de los finos de caseína. El proceso de micro-filtración ha sido muy utilizado en la industria láctea con la misma finalidad, ya que, además de retener los glóbulos de grasa permite la retención de bacterias, extendiendo, de esta forma, el tiempo de vida de los productos obtenidos.

El objetivo de este trabajo fue encontrar el pre-tratamiento más indicado para obtener una eliminación de grasas más eficaz del suero de queso que posibilite una mayor recuperación de lactosa y proteínas.

\section{MATERIALES Y MÉTODOS}

El suero de queso, tipo ácido, utilizado en este trabajo, proviene de la empresa de lácteos Queijos Monte Fuji, localizada en el municipio de Doctor Camargo, PR - Brasil. El suero es procedente de quesos elaborados con leche de vaca. El suero crudo fue inicialmente caracterizado utilizando métodos estándar (A.O.A.C., 2000; Instituto Adolfo Lutz, 2005) para la cuantificación de los siguientes componentes: proteínas, lactosa, grasas, sólidos totales y cenizas. Fue utilizado una única muestra de suero de queso con un volumen de 135 litros, la cual fue congelada en pequeñas porciones (4,5 litros) para la utilización en los experimentos. 
El $\mathrm{pH}$ del suero fue medido utilizando un pH-metro (Digimed - DM20) y para determinar el contenido de sólidos solubles se usó un refractómetro de laboratorio (Shimadzu, Bausch \& Lomb).

\section{Determinaciones analíticas}

Durante el procedimiento experimental fueron analizadas muestras de suero de queso crudo, y las muestras de suero que fueron sometidas al tratamiento para eliminación de grasas. Los análisis de las muestras para determinar el contenido de grasas fueron realizadas en conjunto con la determinación del contenido proteico y de lactosa.

La determinación de la concentración proteica en las muestras, fue realizada utilizando el método de Lowry (Lowry et al., 1951), que es un método bastante utilizado, y se basa en la interacción de las proteínas con el reactivo fenol y cobre en condiciones alcalinas. Para la determinación de la concentración de lactosa fue utilizado el método calorimétrico DNS - Berkeley Modificado (Zanin y Moraes, 1987). Los análisis para determinación del contenido de proteínas y lactosa fueron realizadas por triplicado.

El contenido de grasas fue medido por el método de Gerber (Instituto Adolfo Lutz, 2005), basado en la separación y cuantificación de la grasa por medio de un tratamiento de la muestra con ácido sulfúrico y alcohol isoamílico. Fue utilizada una centrífuga de Gerber (modelo 8 BTF INOX), con capacidad para 8 butirómetros. La determinación del contenido de grasas fue realizada en duplicado.

La determinación de la cantidad de sólidos totales y sólidos solubles fue hecha con dos repeticiones según las normas del Instituto Adolfo Lutz (2005).

El contenido de cenizas fue determinado usando método gravimétrico con muestras por duplicado, según las normas del Instituto Adolfo Lutz (2005). La concentración del calcio y fósforo en las muestras fue determinada por Espectrometría de Absorción Atómica (EAA) en equipo Varian (modelo SpectrAA.10 Plus).

\section{Procesos de pre-tratamiento}

En el proceso de centrifugación fue utilizada una centrífuga JOUAN (modelo C3.12) de fabricación europea. En el soporte de la centrífuga están acoplados 4 recipientes de polipropileno con capacidad individual de $750 \mathrm{ml}$. Inicialmente fueron tomados alrededor de $700 \mathrm{ml}$ del suero crudo en cada recipiente, y posteriormente centrifugado. El suero centrifugado fue separado por filtración en vacío utilizándose papel de filtro cuantitativo. Luego, se procedió a la determinación del contenido de grasa, proteínas y lactosa del suero crudo y del centrifugado de acuerdo con los métodos detallados anteriormente.

Otro proceso de pre-tratamiento evaluado, fue la denominada precipitación termo-cálcica, que fue realizada según la metodología descrita en la literatura (Kim et al., 1989; Karleskind et al., 1995; Pereira et al., 2002). Esta metodología consiste en el ajuste del pH del suero a 7,3-7,5, y adición de 1,2 a $1,4 \mathrm{~g}$ de $\mathrm{CaCl}_{2}$ por litro de suero, y posterior calentamiento de la solución a $50-55^{\circ} \mathrm{C}$, durante un periodo de 8 a 10 minutos. El suero pre-tratado fue utilizado en los experimentos de microfiltración.

\section{Ensayos de eliminación de grasa y determinación de la condición experimental}

Los experimentos de micro-filtración fueron realizados en la unidad MF/UF (NETZSCH), utilizando el principio de filtración tangencial (modelo 027.06-1C1/07-0005/AI). El módulo de filtración utilizado era de acero inoxidable AISI 304, con membrana tubular cerámica de $\alpha-\mathrm{Al}_{2} \mathrm{O}_{3} / \mathrm{ZrO}_{2}$, con diámetro nominal medio de poros de $0,2 \mu \mathrm{m}$, diámetro interno de $7 \mathrm{~mm}$ y área de $0,005 \mathrm{~m}^{2}$. Este módulo está equipado con manómetros en la entrada y la salida para posibilitar el control de la presión transmembrana y acoplado a un baño termo-estático que permite el control de la temperatura de la solución contenida en el tanque de alimentación. 
Se realizaron ensayos de permeación con el suero, para investigar la variación del flujo de permeato con el tiempo, a la presiones de trans-membranas de 1 y 2 bar, y temperaturas de $25^{\circ} \mathrm{C}$ y $50^{\circ} \mathrm{C}$, en las cuatro siguientes condiciones: suero filtrado con filtración en vacío, utilizándose papel filtro cuantitativo (SF); suero centrifugado durante 15 minutos con una fuerza centrífuga relativa (FCR) de $1770 \times \mathrm{g}$ (SC15); suero centrifugado durante 20 minutos con FCR de $1770 \times \mathrm{g}$ (SC20) y suero centrifugado tratado con cloruro de calcio $\left(\mathrm{SC} 20+\mathrm{CaCl}_{2}\right)$. Los ensayos de micro-filtración fueron realizados buscando determinar la mejor condición de operación para eliminación de grasas, que posibilite un mayor aprovechamiento de las proteínas y lactosa del suero.

Los ensayos de micro-filtración fueron realizados usando una cantidad de 4 litros de suero pretratado en cada ensayo, sin retorno de permeato, manteniéndose la velocidad tangencial. Al principio de la filtración, las muestras de permeato fueron colectadas por cortos periodos de tiempo y posteriormente, los intervalos de tiempo fueron aumentados para determinar la curva de flujo de permeato en el tiempo. El flujo de permeato fue medido por diferencia de masa. Muestras de las corrientes de alimentación, permeato y concentrado fueron colectadas para posterior análisis.

El flujo de agua desionizada fue medido antes y después de cada ensayo, a una presión transmembrana de 1 bar y temperatura de $25^{\circ} \mathrm{C}$, para posterior cálculo del coeficiente de fouling. Después de cada ensayo de micro-filtración, la membrana fue sometida a limpieza de acuerdo con las recomendaciones del fabricante. En seguida, el flujo de agua desionizada fue medido, a varias presiones y a temperatura de $25^{\circ} \mathrm{C}$, para verificar si la permeabilidad de la membrana volvía al valor inicial después del proceso de limpieza.

\section{Coeficiente de fouling}

Los ensayos realizados permitieron evaluar el fenómeno de fouling, considerado como el residuo adherido a la membrana y no removido por el enjuague. El coeficiente de fouling fue calculado por la ecuación 1 (Rao, 2002):

$\mathrm{C}_{\mathrm{f}}=1-\frac{\mathrm{J}_{\mathrm{w}}}{\mathrm{J}_{\mathrm{wo}}}$

Donde $C_{f}$ es el coeficiente de fouling (adimensional), $J_{w}$ es el flujo de agua después del enjuague inicial que procede al ensayo con suero $\left(\mathrm{Lh}^{-1} \mathrm{~m}^{-2}\right)$ y $\mathrm{J}_{\mathrm{w} 0}$ es el flujo de agua antes de la realización del ensayo $\left(\mathrm{Lh}^{-1} \mathrm{~m}^{-2}\right)$. Los valores del coeficiente de fouling varían de 0 a 1 , con valor mínimo, para la membrana limpia, y valor máximo para la membrana completamente bloqueada al flujo de permeato.

\section{Resistencia total de la membrana}

Las resistencias debido al fouling y de la capa de polarización fueron determinadas, midiéndose el flujo del suero por medio de la ecuación 2.

$J=\frac{\Delta P}{\eta R_{T}}$

Donde $\mathrm{J}$ es el flujo de permeato $\left(\mathrm{Lh}^{-1} \mathrm{~m}^{-2}\right), \Delta \mathrm{P}$ es el gradiente de presión aplicado a la membrana (bar), $\eta$ es la viscosidad cinemática del permeato (cP) y $R_{\mathrm{T}}$ es la resistencia total al movimiento de permeato $\left(\mathrm{m}^{-1}\right)$. La resistencia total es, generalmente, atribuida a la resistencia intrínseca de la membrana $\left(R_{m}\right)$, resistencia debido a la saturación $\left(R_{c}\right)$ y resistencia debido al depósito sobre la superficie de la membrana $\left(R_{d}\right)$, como muestra la ecuación 3 (Choi et al., 2005). 
$\mathrm{R}_{\mathrm{T}}=\mathrm{R}_{\mathrm{m}}+\mathrm{R}_{\mathrm{c}}+\mathrm{R}_{\mathrm{d}}$

El valor de la resistencia de la membrana a la permeación de agua $R_{m}$, fue considerado constante durante el proceso de micro-filtración y inicialmente fue determinado con agua desionizada, como se muestra en la ecuación 4 . Los valores de los términos $R_{c}$ y $R_{d}$ en la ecuación 3 se consideran nulos para el flujo de agua pura.

$$
\mathrm{R}_{\mathrm{m}}=\frac{\Delta \mathrm{P}}{\eta_{\mathrm{w}} \mathrm{J}_{\mathrm{wo}}}
$$

Donde $\eta_{w}$ y $J_{w o}$ son la viscosidad del agua y el flujo inicial con agua desionizada con la membrana totalmente limpia, respectivamente. Realizando experimentos de micro-filtración con suero, la resistencia total al flujo de permeato, puede ser calculada por la ecuación 2, resultando en:

$$
\mathrm{R}_{\mathrm{T}}=\frac{\Delta \mathrm{P}}{\eta_{\text {suero }} \mathrm{J}_{\mathrm{wf}}}
$$

Donde $J_{w f}$ es el flujo final del suero y $\eta_{\text {suero }}$ es la viscosidad del suero, respectivamente.

La realización de un enjuague con agua después del proceso de permeación del suero, remueve el depósito sobre la membrana, tal que la resistencia Rd puede ser considerada nula. Con una nueva medición del flujo con agua pura $\left(\mathrm{J}_{\mathrm{W}}\right)$ después de este procedimiento de enjuague, y usando las ecuaciones 2 y 3 es posible calcular la resistencia Rc por la ecuación 6.

$\mathrm{R}_{\mathrm{c}}=\frac{\Delta \mathrm{P}}{\eta_{\mathrm{w}} \mathrm{J}_{\mathrm{w}}}-\mathrm{R}_{\mathrm{m}}$

Luego, con Rm y Rc conocidos y utilizando la ecuación 3, se tiene;

$\mathrm{R}_{\mathrm{d}}=\mathrm{R}_{\mathrm{T}}-\left(\mathrm{R}_{\mathrm{m}}+\mathrm{R}_{\mathrm{c}}\right)$

\section{RESULTADOS Y DISCUSIÓN}

El pH del suero fue medido, obteniéndose valores en el rango de 4,0-5,0, lo que caracteriza un suero ácido. La Tabla 1, muestra los resultados encontrados para el suero de queso ácido (Monte Fuji), y los resultados encontrados en la literatura, presentados como porcentaje de los sólidos totales (\% ST).

Es importante resaltar que en el suero de queso (Monte Fuji) utilizado en este trabajo, el contenido de grasa es mayor, y los contenidos de calcio y fósforo son menores de los correspondientes contenidos presentados en la literatura. 
Tabla 1: Composición del suero de queso tipo ácido (1* - Antunes, 2003; $2^{*}$ - Nakay y Modler, 2000)

\begin{tabular}{llll}
\hline \multirow{2}{*}{ Componentes } & \multicolumn{3}{c}{ Suero de queso ácido } \\
\cline { 2 - 4 } & Monte Fuji (\%ST) & $1^{*}(\% \mathrm{ST})$ & $2^{*}(\% \mathrm{ST})$ \\
\hline Sólidos Solubles & $6,8 \pm 0,15$ & - & 6,48 \\
\hline Sólidos Totales & $6,5 \pm 0,15$ & 6,20 & 0,76 \\
Proteínas & $0,85 \pm 0,05$ & 0,75 & 4,86 \\
Lactosa & $4,94 \pm 0,47$ & 4,20 & 0,09 \\
Grasa & $0,49 \pm 0,07$ & 0,04 & 0,61 \\
Cenizas & $0,57 \pm 0,03$ & 0,80 & 0,103 \\
Calcio & 0,045 & 0,125 & 0,078 \\
Fósforo & 0,040 & 0,065 & \\
\hline
\end{tabular}

Flujo de permeación

Un parámetro importante que caracteriza el desempeño de un sistema que utiliza membranas es el flujo de permeato. Para una presión trans-membrana de 1 bar y temperatura de $25^{\circ} \mathrm{C}$, el flujo medio inicial y la permeabilidad media inicial (con agua desionizada) fueron de $3395 \mathrm{Lh}^{-1} \mathrm{~m}^{-2}$ y $9,43 \times 10^{-04}$ $\mathrm{ms}^{-1} \mathrm{bar}^{-1}$, respectivamente. Durante 2,5 horas de filtración se observó una disminución de $40 \%$ del flujo inicial.

Las Figuras 1, 2, 3 y 4 muestran el comportamiento del flujo de permeato del suero en las diferentes condiciones de pre-tratamientos, diferentes temperaturas y presiones trans-membranas, para una membrana de $0,2 \mu \mathrm{m}$.

La Figura 1, muestra que hubo una elevada reducción del flujo en los primeros minutos de procesamiento del suero centrifugado durante 15 y 20 minutos, usando presión trans-membrana de 2 bar. El coeficiente de fouling encontrado, en estas condiciones fue de 0,96 , siendo que para el suero centrifugado durante 15 y 20 minutos a 1 bar, fue de 0,88 y 0,89, respectivamente. Presiones más elevadas resultaron en mayores flujos iniciales de permeato, sin embargo estos flujos cuando son estabilizados, prácticamente tienen un orden de valores similares a aquellos para menor presión. Probablemente puede haber ocurrido una mayor retención en la membrana en presiones más elevadas, lo que redujo el diámetro de los poros y consecuentemente causó una reducción de la permeabilidad de la membrana (Beolchini et al., 2004).

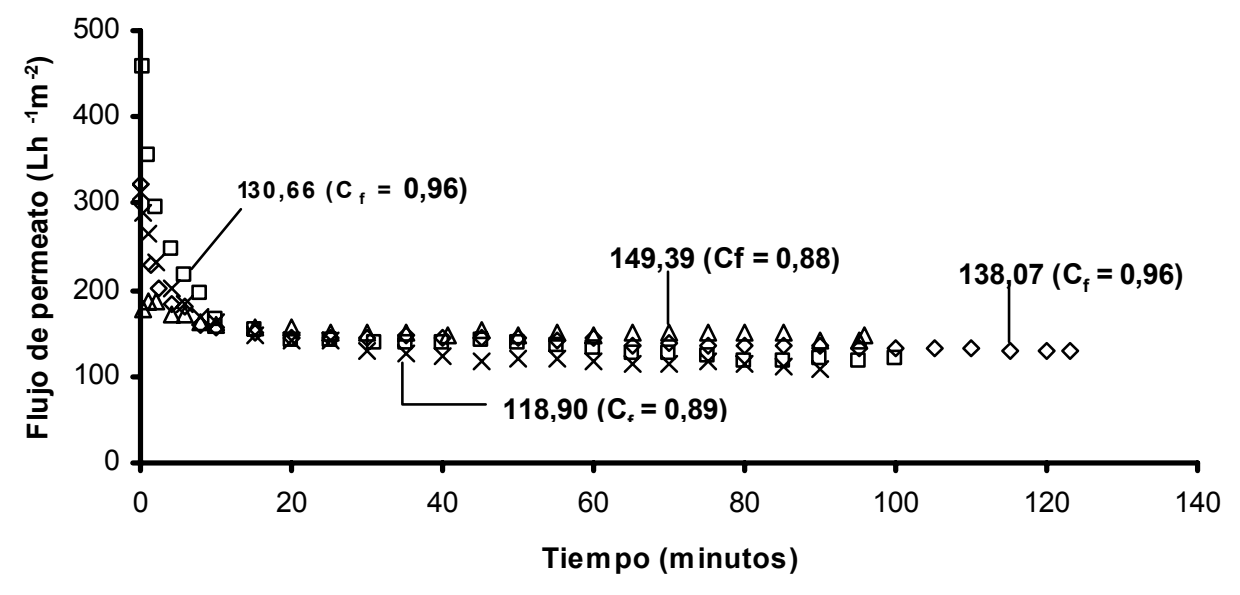

Fig. 1: Variación del Flujo de Permeato del Suero Centrifugado $\left(25^{\circ} \mathrm{C}\right)$. Las curvas corresponden a: × SC20-1 bar; $\square$ SC20-2 bar; $\Delta$ SC15-1 bar; $\diamond$ SC15-2 bar

La Figura 2, muestra la variación del flujo de permeato cuando fue utilizado suero centrifugado durante 20 minutos (FCR de $1170 \times \mathrm{g}$ ), presión de trans-membrana de 1 bar y temperaturas de $25^{\circ} \mathrm{C}$ y $50^{\circ} \mathrm{C}$. Temperaturas más elevadas implicaron mayores flujos de permeato, sin embargo esta 
diferencia no fue significativa para los flujos medios estabilizados de permeato en relación al tiempo operacional. Los coeficientes de fouling encontrados para las temperaturas de $25^{\circ} \mathrm{C}$ y $50^{\circ} \mathrm{C}$ fueron de 0,89 y 0,96 , respectivamente. Así, el hecho de que el flujo a $50^{\circ} \mathrm{C}$ presenta un mayor coeficiente de fouling y también que los flujos estabilizados tienen prácticamente los mismos valores de los flujos estabilizados a $25^{\circ} \mathrm{C}$, la temperatura a $50^{\circ} \mathrm{C}$ no fue considerada.

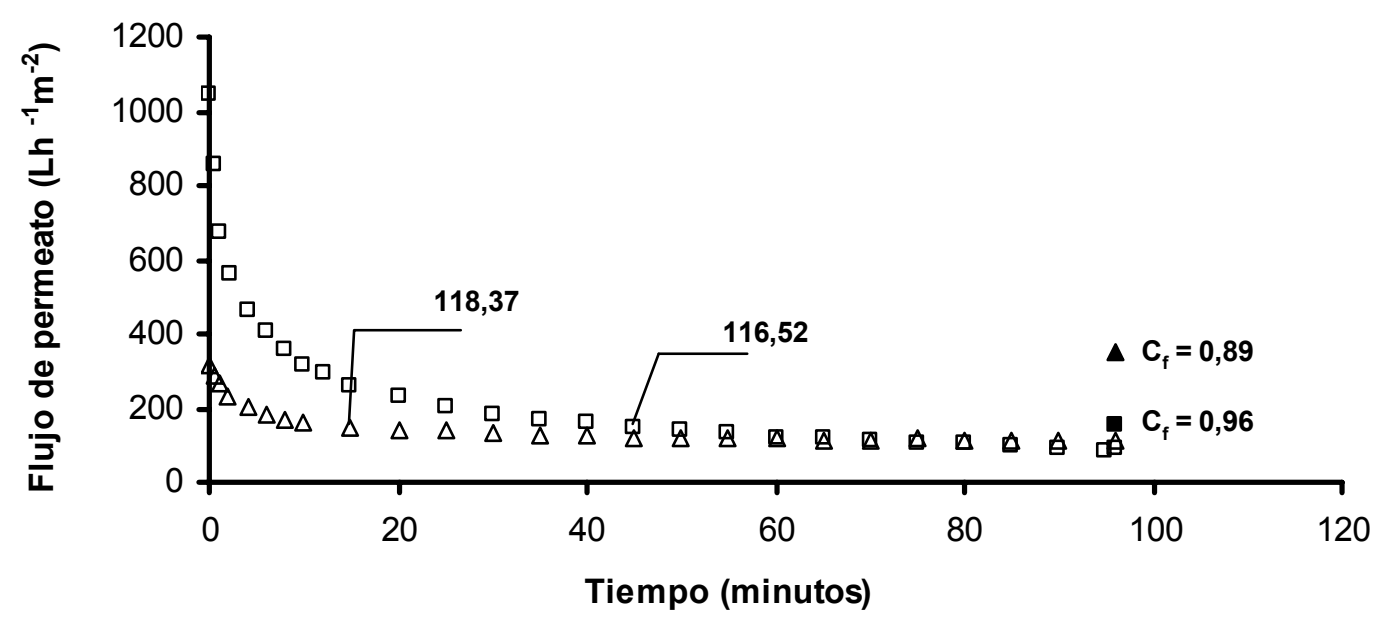

Fig. 2: Variación del flujo de Permeato del Suero Centrifugado $\left(\Delta \mathrm{T}=25^{\circ} \mathrm{C} ; \boldsymbol{\Delta}\right.$ Flujo con agua después del enjuague; $\square \mathrm{T}=50^{\circ} \mathrm{C}$; — Flujo con agua después del enjuague)

Como se observa en la Figura 3, el suero centrifugado y tratado con cloruro de calcio, mostró un menor coeficiente de fouling, cuando se utilizó 1 bar de presión a $25^{\circ} \mathrm{C}$. El flujo inicial de permeato para el suero tratado a 2 bar de presión es cerca de 55\% mayor que el flujo inicial del suero tratado con 1 bar. Por otro lado, la variación no es tan significativa para los flujos medios estabilizados de permeato en relación al tiempo.

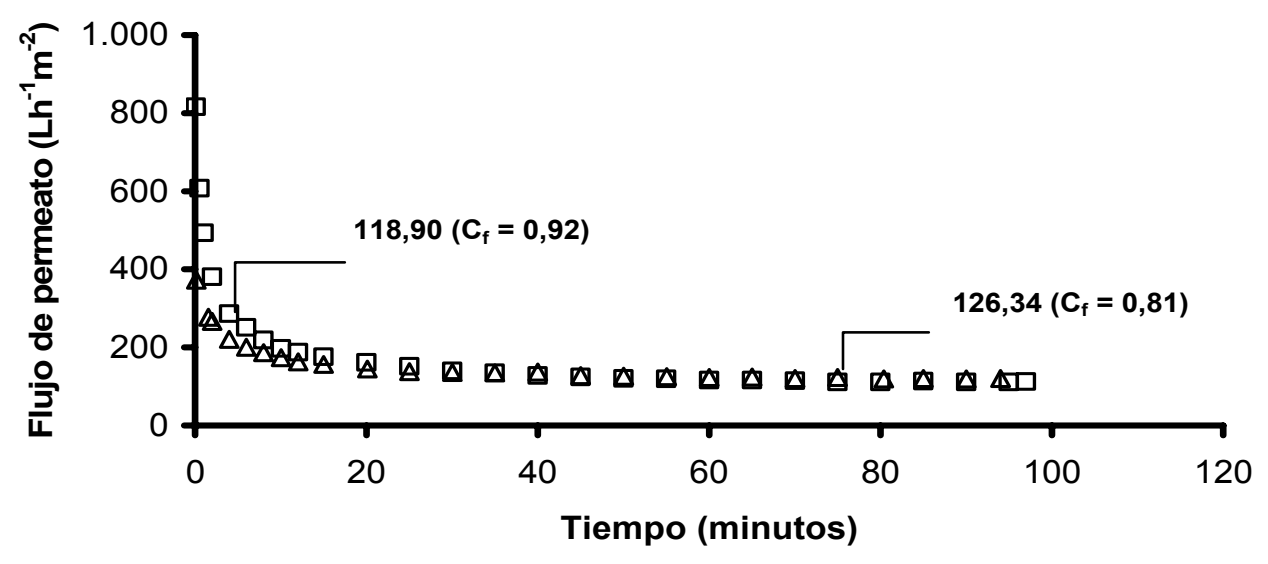

Fig. 3: Variación del Flujo de Permeato del Suero tratado con $\mathrm{CaCl}_{2}(\Delta 1$ bar; $\square 2$ bar $)$

La Figura 4, muestra la variación de flujo con el tiempo para todas las condiciones de pre-tratamiento del suero de queso, cuando se utilizó 1 bar a $25^{\circ} \mathrm{C}$. El flujo medio de permeato para el suero filtrado fue de aproximadamente $93 \mathrm{Lh}^{-1} \mathrm{~m}^{-2}$. Los flujos medios de permeato para el suero centrifugado, durante 15 y 20 minutos, y para el suero tratado con cloruro de calcio se encuentran en la misma escala de variación, por lo tanto no son significativas. Por otro lado, el menor coeficiente de fouling encontrado fue para la condición de suero tratado con cloruro de calcio a $25^{\circ} \mathrm{C}$ y presión de 1 bar. 


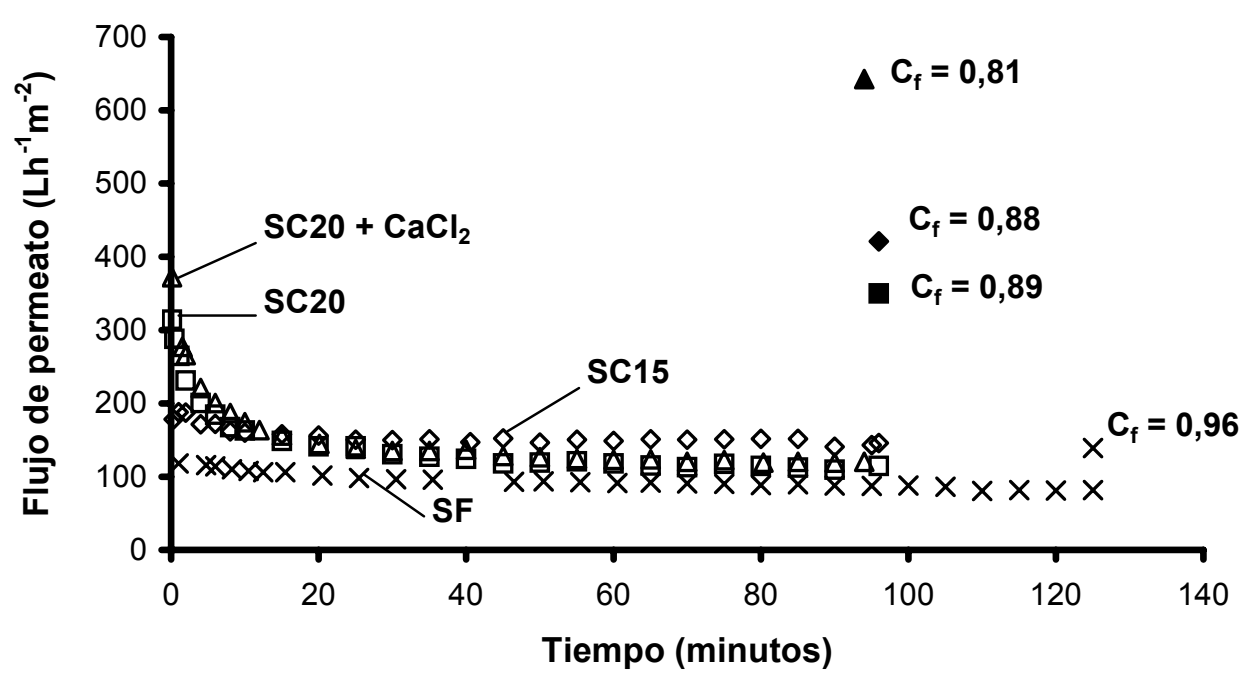

Fig. 4: Variación del Flujo de Permeato del Suero a $\mathrm{P}=1$ bar y $\mathrm{T}=25^{\circ} \mathrm{C}$ ( $\square$ Flujo con suero; $\square$ Flujo con agua después del enjuague)

La Tabla 2 presenta los flujos medios estabilizados de permeato y los coeficientes de fouling a temperatura de $25^{\circ} \mathrm{C}$ y presiones de 1 y 2 bar.

Tabla 2: Flujos medios estabilizados de permeato y coeficientes de fouling

\begin{tabular}{lllll}
\hline Pre-tratamiento - Suero & Temp. $\left({ }^{\circ} \mathrm{C}\right)$ & Presión (bar) & Flujo Medio $\left(\mathrm{Lh}^{-1} \mathrm{~m}^{-2}\right)$ & $\mathrm{C}_{\mathrm{f}}$ \\
\hline $\mathrm{SF}$ & 25 & 1 & $95,33 \pm 10,84$ & 0,96 \\
\hline \multirow{2}{*}{$\mathrm{SC} 15$} & 25 & 1 & $149,39 \pm 3,68$ & 0,88 \\
& 25 & 2 & $138,07 \pm 6,07$ & 0,96 \\
\hline \multirow{2}{*}{$\mathrm{SC} 20$} & 25 & 1 & $118,37 \pm 5,91$ & 0,89 \\
& 25 & 2 & $130,66 \pm 9,67$ & 0,96 \\
\multirow{2}{*}{$\mathrm{SC} 20+\mathrm{CaCl}_{2}$} & 25 & 1 & $126,34 \pm 6,77$ & 0,81 \\
& 25 & 2 & $118,90 \pm 8,92$ & 0,92 \\
\hline
\end{tabular}

El suero que fue solamente filtrado SF, presentó un menor flujo a través de la membrana de microfiltración, que es una desventaja para el proceso. Los flujos para las otras condiciones de prétratamiento son del mismo orden de magnitud, pero se observa que para las presiones de 2 bar el coeficiente de fouling es mayor. Así es preferible operar el micro-filtración con la menor presión.

La Tabla 3 muestra los valores medios del contenido de proteínas y lactosa, y los correspondientes porcentajes de pérdida de proteína y lactosa, y de eliminación de grasas, para cada pre-tratamiento investigado. Los valores presentados fueron calculados de acuerdo con los valores medios encontrados para el suero crudo, mostrados en la Tabla 1.

Tabla 3: Contenido y pérdida de proteínas y lactosa, y eliminación de grasa

\begin{tabular}{|c|c|c|c|c|c|}
\hline \multirow[b]{2}{*}{$\begin{array}{c}\text { Pre-tratamiento - } \\
\text { Suero }\end{array}$} & \multicolumn{2}{|c|}{ Proteína } & \multicolumn{2}{|c|}{ Lactosa } & \multirow[b]{2}{*}{$\begin{array}{c}\text { Grasa } \\
\text { (\%eliminación) }\end{array}$} \\
\hline & $\begin{array}{l}\text { Contenido } \\
\left(\mathrm{gL}^{-1}\right)\end{array}$ & $\begin{array}{l}\text { Pérdida } \\
(\%)\end{array}$ & $\begin{array}{l}\text { Contenido } \\
\left(\mathrm{gL}^{-1}\right)\end{array}$ & $\begin{array}{l}\text { Pérdida } \\
(\%)\end{array}$ & \\
\hline SF & $8,00 \pm 0,32$ & 5 & $41,37 \pm 0,91$ & 16 & $\sim 15$ \\
\hline SC15 & $8,00 \pm 0,82$ & 5 & $44,96 \pm 7,15$ & 10 & $\sim 60$ \\
\hline SC20 & $7,36 \pm 0,73$ & 14 & $44,58 \pm 7,67$ & 10 & $\sim 80$ \\
\hline $\mathrm{SC} 20+\mathrm{CaCl}_{2}$ & $7,21 \pm 0,28$ & 10 & $40,09 \pm 0,58$ & 19 & $\sim 80$ \\
\hline
\end{tabular}

El proceso de filtración común (SF) no es un tratamiento eficiente, tomando en cuenta que la eliminación de grasas del suero crudo es muy baja. La centrifugación remueve cerca de 60 a $80 \%$ de 
la grasa. Esta etapa es necesaria en el proceso de aprovechamiento de proteínas y lactosa. Los resultados obtenidos muestran que el suero tratado con cloruro de calcio, a pesar de presentar un menor coeficiente de fouling, exhibe una mayor pérdida de lactosa ( 19\%).

\section{Resistencia de la membrana de micro-filtración}

En la Tabla 4 se encuentran los resultados de resistencia total, y los porcentajes individuales de cada resistencia al flujo de permeato de suero pre-tratado.

Tabla 4: Contribución de las resistencias: intrínseca de la membrana, de colmatación, y de depósito para la resistência total (membrana de 0,2 $\mu \mathrm{m}$ )

\begin{tabular}{|c|c|c|c|c|c|}
\hline & Presión (bar) & $\mathrm{R}_{\mathrm{T}}\left(\mathrm{x} 10^{11} \mathrm{~m}^{-1}\right)$ & $R_{m}(\%)$ & $\mathrm{R}_{\mathrm{c}}(\%)$ & $\mathrm{R}_{\mathrm{d}}(\%)$ \\
\hline SF & & 30,44 & 3,78 & 91,10 & 5,12 \\
\hline SC15 & 1 & 16,99 & 6,65 & 49,74 & 43,67 \\
\hline SC20 & 1 & 21,62 & 5,46 & 47,78 & 46,76 \\
\hline $\mathrm{SC} 20+\mathrm{CaCl}_{2}$ & & 20,62 & 5,72 & 24,68 & 69,59 \\
\hline SC15 & & 38,42 & 2,94 & 78,42 & 18,64 \\
\hline SC20 & 2 & 41,62 & 2,93 & 70,18 & 26,89 \\
\hline $\mathrm{SC} 20+\mathrm{CaCl}_{2}$ & & 44,04 & 2,57 & 68,42 & 29,02 \\
\hline
\end{tabular}

De acuerdo con los resultados presentados en la Tabla 4, se verifica que no siempre un único mecanismo de fouling es dominante. Las resistencias totales (Tabla 4) y los coeficientes de fouling (Tabla 2) son mayores para las condiciones de presión de 2 bar. Para esta presión la resistencia debido a la saturación, es la principal responsable por la resistencia al flujo de permeato. Esta resistencia es menos influyente para presión de 1 bar. La excepción se hace cuando el suero fue solamente filtrado antes de la permeación. La condición de suero centrifugado y tratado con cloruro de calcio, en 1 bar fue la que presentó menor contribución de saturación.

\section{CONCLUSIONES}

De acuerdo con los flujos medios obtenidos, se observa que la mejor condición de operación ocurriría cuando se lleva a cabo el tratamiento con $\mathrm{CaCl}_{2}$ del suero centrifugado, a 1 bar y $25^{\circ} \mathrm{C}$. Es en esta condición se obtienen flujos más altos y un menor coeficiente de fouling. Por otro lado, bajos las mismas condiciones, de acuerdo con los análisis físico-químicos, se observa que la pérdida de lactosa es mayor que en el suero centrifugado (SC20).

Como el objetivo de este trabajo consistió en la busca de tratamiento más efectivo para eliminación de grasas y mayor aprovechamiento de proteínas y lactosa, se optó por trabajar con suero centrifugado $\left(25^{\circ} \mathrm{C}\right.$ y 1 bar $) \sin$ tratamiento con $\mathrm{CaCl}_{2}$.

El proceso de centrifugación demostró ser una etapa necesaria, ya que remueve entre 60 y $80 \%$ de la grasa del suero crudo. El proceso de micro-filtración complementa la centrifugación en lo que se refiere a la eliminación total de grasa, y combinado con la centrifugación permitió una recuperación media de $90 \%$ de la lactosa del suero de queso.

\section{REFERENCIAS}

Antunes, A.J., Funcionalidade de Proteínas do Soro de Leite Bovino, 1ª editión, 135 p. Manole, Barueri, São Paulo, Brasil (2003).

A.O.A.C.; Official Methods of Análisis, $17^{\mathrm{a}}$ edición, CD ROM. Association of Official Analytical Chemists, Gaethersburg (2000).

Atra, R.; G. Vatai; E.B. Molnar y A. Balint; Investigation of ultra- and nanofiltration for utilization of whey protein and lactose, Journal of Food Engineering: 67 (3), 325-332 (2005). 
Beolchini, F.; F. Veglio y D. Barba; Microfiltration of bovine and ovine milk for the reduction of microbial content in a tubular membrane: a preliminary investigation, Desalination: 161 (3), 251-258 (2004).

Brião, V.B.; Processos de separação por membranas para reuso de efluentes de laticínios, Tesis de Doutorado, Dpto. Eng. Química, UEM, Maringá, Brasil (2007).

Bund, R.K. y A.B. Pandit; Rapid lactose recovery from buffalo whey by use of anti-solvent, ethanol, Journal of Food Engineering: 82 (3), 333-341 (2007).

Choi, H. y otros cuatro autores; Effect of permeate flux and tangential flow on membrane fouling for wastewater treatment, Separation and Purification Technology, Amsterdan: Elsevier Science: 45 (1), 68-78 (2005).

Chollangi, A. y Md.M. Hossain; Separation of proteins and lactose from dairy wastewater, Chemical Engineering and Processing: 46 (5), 398-404 (2007).

Instituto Adolfo Lutz; Métodos físico-químicos para análise de alimentos, 4 ${ }^{\mathrm{a}}$ edición, 1018 p. Ministerio da Saúde, Agência Nacional de Vigilancia Sanitária, Brasilia, Brasil (2005).

Karleskind, D.; I. Laye; F-I Mei y C.V. Morr; Chemical Pretreatment and Microfiltration for Making Delipized Whey Protein Concentrate, Journal of Food Science: 60 (2), 221-226 (1995).

Kim, S-H; C.V. Morr; A. Seo y J.G. Surak; Effect of Whey Pretreatment on Composition and Functional Properties of Whey Protein Concentrate, Journal of Food Science: 54 (1), 25-29 (1989).

Lowry, O.H.; N.J. Rosebrough; A.L. Farr y R.J. Randall; Protein Measurement with the Folin Phenol Reagent, The Journal of Biological Chemistry: 193 (1), 265-275 (1951).

Muñi, A. y otros cuatro autores; Eficiência de um sistema de ultrafiltración/nanofiltración tangencial em serie para el fraccionamento y concentración del lactosuero, Revista Científica: 15 (4), 361-367 (2005).

Nakay,S. y W.H. Modler; Food Proteins: Processing Applications. Wiley-VCH, Inc., United States of America (2000).

Pereira, C.D.; O. Diaz y A. Cobos; Valorization of by-products from ovine cheese manufacture: clarification by thermocalcic precipitation/microfiltration before ultrafiltration, International Dairy Journal: 12 (9), 773-783 (2002).

Rao, R.H.G.; Mechanisms of flux decline during ultrafiltration of dairy products and influence of $\mathrm{pH}$ on flux rates of whey and buttermilk, Desalination: 144 (1-3), 319-324 (2002).

Richards, N.S.P.S.; Soro Lácteo: Perspectivas Industriais e Proteção ao Meio Ambiente, Revista Foods Ingredients, São Paulo, Brasil: 3 (17), 20-27 (2002).

Zanin, G.M. y F.F. Moraes; Tecnologia de Imobilização de Células e Enzimas Aplicada à Produção de Álcool de Biomassas, Relatório n², 315-321 (1987). 